\title{
B. John Davies Best Paper Prize for papers published in IJAMT 2015
}

\author{
Anthony Doyle ${ }^{1}$ - Andrew Y. C. Nee $^{2}$
}

Published online: 18 November 2016

(C) Springer-Verlag London 2016

It is our pleasure to announce the B. John Davies Best Paper Prize, named after late Prof John Davies who was the founding Editor-in-Chief of IJAMT, for the most outstanding paper published in IJAMT 2015.

This is awarded to:

Wanqun Chen, Lihua Lu, Hao Su, and Qingchun Zhang

Center for Precision Engineering, Harbin Institute of Technology, Harbin 150001, People's Republic of China

Kai Yang Army Aviation Institute, Beijing 101123, People's Republic of China

Dehong Huo, School of Mechanical and Systems Engineering, Newcastle University,

Newcastle upon Tyne NE1 7RU, UK

for their co-authored paper "A novel machine tool design approach based on surface generation simulation and its implementation on a fly cutting machine tool", published in the Int J Adv Manuf Technol (2015) 80:829-837.
This is arrived at after rigorous reviews by the editors, basing on the reviewers' comments and nomination. The paper is judged to have excellent academic value as well as application potential in the industry.

A certificate and US\$5000 in recognition of their exceptional and original research effort is presented to them by Springer.

In 2015, IJAMT received a total of 3794 submissions and 1544 papers were accepted for publication.

The Editors would like to encourage quality submissions and are looking forward to presenting the B. John Davies Best Paper Prize in the future years.

Anthony Doyle

Executive Editor, Springer

Andrew Y C Nee

Editor-in-Chief, IJAMT
Anthony Doyle

anthony.doyle@springer.com

Andrew Y. C. Nee

mpeneeyc@nus.edu.sg

1 Springer-Verlag London Ltd, 236 Gray's Inn Road, Floor 6, London WC1X 8HL, UK

2 National University of Singapore, 9 Engineering Drive 1, Singapore 117576, Singapore 